\title{
Frame Construction and Task Analysis of Smart Energy in the Construction of Smart City
}

\author{
Linyu Wang1,2, Jiawei Zhou1, Hui Qi3 ${ }^{3}$ Yifan Ding1, Junping Yin'1 \\ ${ }^{1}$ State Grid (Suzhou) City \& Energy Research Institute, Suzhou, China \\ ${ }^{2}$ State Grid Energy Research Institute, Beijing, China \\ ${ }^{3}$ State Grid Taizhou Power Supply Company, Taizhou, China \\ Email: 15205161411@163.com
}

How to cite this paper: Wang, L.Y., Zhou, J.W., Qi, H., Ding, Y.F. and Yin, J.P. (2020) Frame Construction and Task Analysis of Smart Energy in the Construction of Smart City. Energy and Power Engineering, 12, 25-36.

https://doi.org/10.4236/epe.2020.124B003

Received: January 5, 2020

Accepted: April 7, 2020

Published: April 10, 2020

\begin{abstract}
Smart energy is the foundation and important component of smart cities, and it is the source of energy that guarantees the efficient and reliable operation of each subsystem of the city. Based on the practical experience in the exploration of the construction of smart energy at home and abroad, and the goal of achieving "three transformations and one center", the basic principles of the frame construction as well as display construction and physical construction of smart energy have been proposed. Four main tasks of the construction of smart energy have been discussed: infrastructure, energy supply, energy consumption, and management services.
\end{abstract}

\section{Keywords}

Smart Energy, Smart City, Display Construction, Physical Construction

\section{Introduction}

In June 2014, General Secretary Xi Jinping put forward the "Four Revolutions, One Cooperation" energy strategy at the sixth meeting of the Central Finance and Economics Leading Group. China's cities have nearly $60 \%$ of the population and consume about $85 \%$ of energy. It is the main battlefield of the national energy revolution, and continues to promote the implementation of the national energy revolution. In 2017, the " $19^{\text {th }}$ National Congress" report once again emphasized that the energy production and consumption revolution will be promoted, and a clean, low-carbon, safe and efficient energy system will be built. The construction of smart energy is an effective driver of the energy revolution, 
which will directly reduce the cost of urban energy consumption and ensure the basic safety of energy consumption, and make the environment more sustainable for energy consumption. It will indirectly achieve high-quality sustainable development of cities. At the same time, the country is also making efforts to build smart cities. In 2012, the Ministry of Housing and Construction officially launched the pilot of smart cities. In 2014, smart cities were included in the national strategic plan for the first time. At the end of 2015, after 37 years, the central government again held urban work conference which signified that the construction of smart cities has entered a new stage of development. The announced "Guiding Opinions on Further Promoting the Reform of the Urban Law Enforcement System and Improving Urban Management" explicitly proposed "building a smart city" and "taking the opportunity of the construction of smart city to give full play to the advantages of modern information technology and accelerate the formation of the ability of urban management to match economic and social development". Smart energy is an important part of smart cities and the construction of smart cities will promote the development of smart energy [1].

City smart energy is based on the entire life cycle of energy in the city, that the cycle involves interconnection and sharing of object information. Through perception, analysis, and optimization, it forms a new model of energy system characterized by full sharing of information resources, accurate and efficient application management, and reasonable and stable system allocation. Construct an optimized, reasonable, safe and advanced energy structure in terms of structure, scale, economy, energy saving, environmental protection and services. The core system is a user-centered system including energy Internet + shared energy data platform + extensively participating business models and new business formats + low-carbon and efficient energy use, involving concepts, technologies, management and other aspects. It takes the Internet of Energy as the core and is based on a new business model and business format with multiple parties as the pillar. It focuses on promoting the development of a shared energy platform and aims to achieve a low-carbon and efficient energy economy and convenient and inclusive energy services.

\section{Overview of the Construction of Smart Energy at Home and Abroad}

From a global perspective, there are many aspects of the development of smart cities and smart energy. Foreign countries are leading the exploration and development of smart cities and smart energy, for example, Vienna, Austria [2], New York, and Singapore [3] rank in the forefront of the world. They can develop local endowments according to local conditions and have achieved world-leading utilization efficiency and management of integrated energy systems. Energy Revolution and the Construction of Smart Energy of Suzhou takes the lead in China. 


\begin{tabular}{|c|c|c|c|}
\hline City & Background & Measures & Effect \\
\hline Vienna & $\begin{array}{l}\text { a long history, aging infrastructure, } \\
\text { complex social management, } \\
\text { building energy consumption and } \\
\text { transportation energy consumption } \\
\text { account for more than } 70 \% \text { of final }\end{array}$ & $\begin{array}{l}\text { Macro management of urban energy systems, high-efficiency } \\
\text { production and supply technologies, intelligent networks and } \\
\text { thermal energy supply, dynamic buildings with low energy demand, } \\
\text { develop environmentally-friendly, energy-efficient, and low-carbon } \\
\text { emission activity systems. }\end{array}$ & $\begin{array}{l}\text { Vienna's urban population } \\
\text { accounts for } 20 \% \text { of the country, } \\
\text { and its energy consumption } \\
\text { accounts for only } 12 \% \text { - } 14 \% \text { of the } \\
\text { country. }\end{array}$ \\
\hline
\end{tabular}

New York GDP reached USD 900.7 billion in 2017, extremely dense urban population, inconsistency between energy consumption and economic development, outdated energy infrastructure and excessive investment costs for upgrading.

Singapore lack of local resources, highly urbanized countries, small land area and high population density.
Improve the organization structure of urban energy management. Fine and strict control of energy management processes to enhance urban energy security capabilities.

Improve urban energy use efficiency and promote the use of new energy.

Study the potential of waste production capacity to improve energ efficiency.

The world's largest floating photovoltaic power plant was established in 2016.

Develop standards in a variety of industries, including the construction industry.

Promote innovative industries, apply digital technology to build urban smart energy systems.

Innovate scientific research mechanism.

Suzhou

Suzhou's energy conservation and consumption reduction work in the industrial, transportation, and construction fields started earlier, gather leading technologies, innovative equipment and emerging industries

Xiong'an

rich in clean energy resources such as geothermal energy, photovoltaics and biomass, large scale renewable energy generation capacity, alternative resources with natural gas pipelines and underground gas storage, will create high-quality energy demand. terminal energy consumption, control the total coal consumption,
1) On the energy consumption side, promote clean substitution of and reduce the pollution of scattered coal and scattered oil on cities. 2) Through the construction of the Industrial Internet of Things, the introduction of top companies in the field of industrial

intelligence such as Alibaba and China Mobile Big Data Research Institute will create an efficient and green industrial system, transportation system and building system on the energy consumption side.

3) Fully develop and utilize local clean energy on the energy supply side, promote distributed energy management, make full use of the excellent resources of local enterprises, such as GCL, etc., carry out the construction of future science and technology museums, publicize future smart energy application scenarios, and establish demonstration projects.

4) The energy transmission link further develops a strong smart grid, promotes the interaction between the source and the grid, and strengthens the storage and transportation capacity of natural gas and refined oil

Create a zero-carbon smart green energy system, and

simultaneously create two worlds (physical world and data virtual world) from two dimensions (hardware infrastructure and institutional soft environment). Make full use of the advantages of clean energy resources such as geothermal energy and realize complementary with multi-energy such as external green power and natural gas. Comprehensively adopt the principles and technical system of energy internet, multi-energy synergy, "source-network-load-storage" synergy, centralized and distributed synergy, and planning-construction-operation-management synergy. In accordance with smart cities' cell body energy station-cluster-network model, gradually build a new district terminal energy supply and demand system. Innovate energy systems and policies and meet the high-quality energy needs brought by high-quality economic development.
The New York City Energy Sustainable Development Strategy focuses on the long-term planning of 2030 , and guarantees to achieve the expected strategic goal of reducing emissions by $30 \%$ by 2030.

The most widely used WtE technology has been used to meet $3 \%$ of Singapore's electricity demand. $60 \%$ of the waste in Singapore is recycled, $38 \%$ of the waste is used to generate electricity, and only $2 \%$ of the waste is sent to landfills.

Coal accounted for $60 \%$ of primary energy consumption in Suzhou, and the proportion of clean energy continued to increase, reaching $9.48 \%$, electricity accounted for $28.3 \%$ of terminal energy consumption

At the stage of transformation and upgrading, the total energy consumption of residents and per capita are leading, and the energy consumption structure is gradually shifting to the transportation and construction fields

It has recently achieved "carbon neutrality", and will completely rely on renewable energy to achieve zero carbon emissions by 2040 .

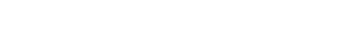

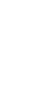




\section{Frame Construction of Smart Energy}

\subsection{The Basic Principle}

The construction of smart energy needs to adhere to the basic principles of "co-construction, co-governance, and sharing."

"Co-construction" is reflected in government guidance, business leadership, and public participation.

"Co-governance" is reflected in everyone's participation, everyone's responsibility, and co-governance and integration through participation.

"Sharing" means insisting on inclusive sharing, gaining benefits from each other, strengthening cost-benefit analysis, and ensuring that all parties are shared with the construction results.

\subsection{Presentation Construction}

City smart energy is an energy system that uses informatization, digitalization, and intelligentilization to achieve extensive network interconnection, flexible user participation, multi-energy collaborative operation, support for a large proportion of clean energy development and utilization, and the emergence of new business forms. Its essential feature is "three transformations and one center", that is, digitalization, intelligentilization, greenness, which takes high-quality urban development as the center [4].

The display construction of city smart energy includes five aspects. The development direction of the energy system is clean and low-carbon, safe and efficient, flexible and convenient. The system construction is vertical layered coordination, horizontal multi-link, and deep integration of physics-information-application. The operation mechanism is data-driven, market guidance, sustainable development through institutional change and business model innovation. The forms of manifestation are smart supply, smart consumption, smart service, smart management, etc. The content takes electricity as the core and aims to achieve multi-energy complementarity. The grid is taken as the platform that supports the construction of energy Internet accompanied by "source-network-load-storage". Presentation construction of the smart energy is shown in Figure 1.

\subsection{Physical Construction}

The physical construction is mainly summarized as "three layers and three levels" from the vertical and horizontal directions. It also includes the business model and guarantee mechanism that run through the whole, and the content of the presentation construction is realized through the realization of the physical construction. The "three levels" includes the physical layer, the information layer, and the application layer, corresponding to the basic perception layer, information resource layer, and fusion and coordination layer in the construction of smart city. The "three levels" includes three different geographic ranges: users, parks, and cities. Physical layered construction of smart energy is shown in Figure 2. 


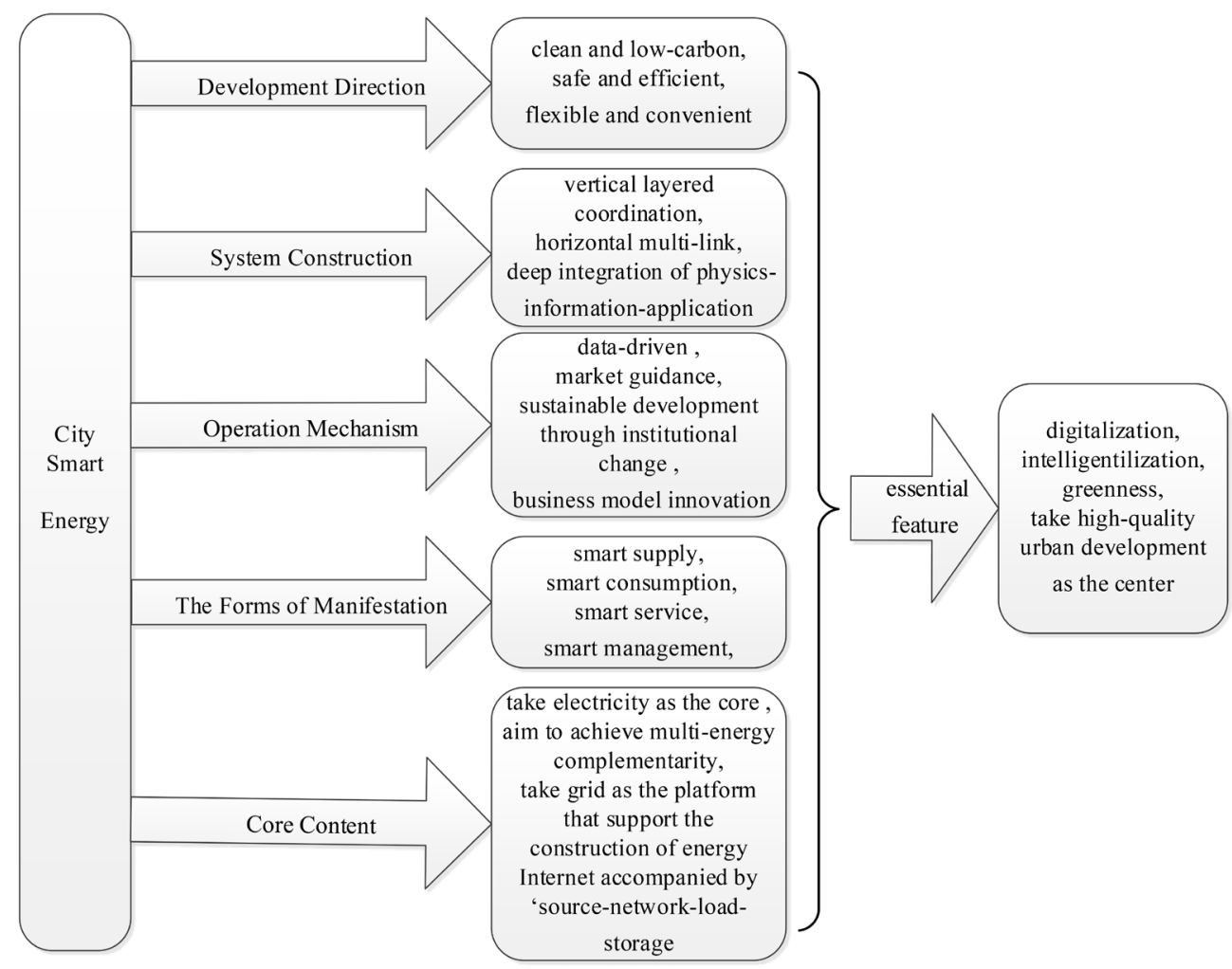

Figure 1. Frame construction of smart energy.

The construction of the physical layer and the information layer mainly realizes the goal of digitalization and intelligentization of smart energy. The construction of the application layer aims to achieve greenness. Based on the three-layer construction, it guides related industries and services from inside to outside to develop in the right direction, and ultimately supports the high-quality development of Taizhou.

The physical layer is mainly to build an information-aware system and transmission system based on the current basic energy network. It focus on the improvement of the network and the construction of information capture and transmission networks. In terms of city energy infrastructure, one is the intelligentization of the city-wide energy transmission network, including the intelligentization of the nodes of the city power transmission network and the intelligentization of the gas transmission network. The other is the intelligent upgrade of energy conversion facilities, including power plants, the improvement of transformation facilities such as energy stations. The third is the intelligent upgrade of terminal energy-consuming equipment from the plant to the building and from transportation to users, and form a complete smart energy chain.

The information layer is mainly to build systems and platforms for data storage, cleaning, and sharing. The layer includes data that needs unified storage management and data collection that is unique to each energy subsystem and application subsystem, as well as corresponding sharing and fusion mechanisms and interfaces. Start with a network or users with a good development 


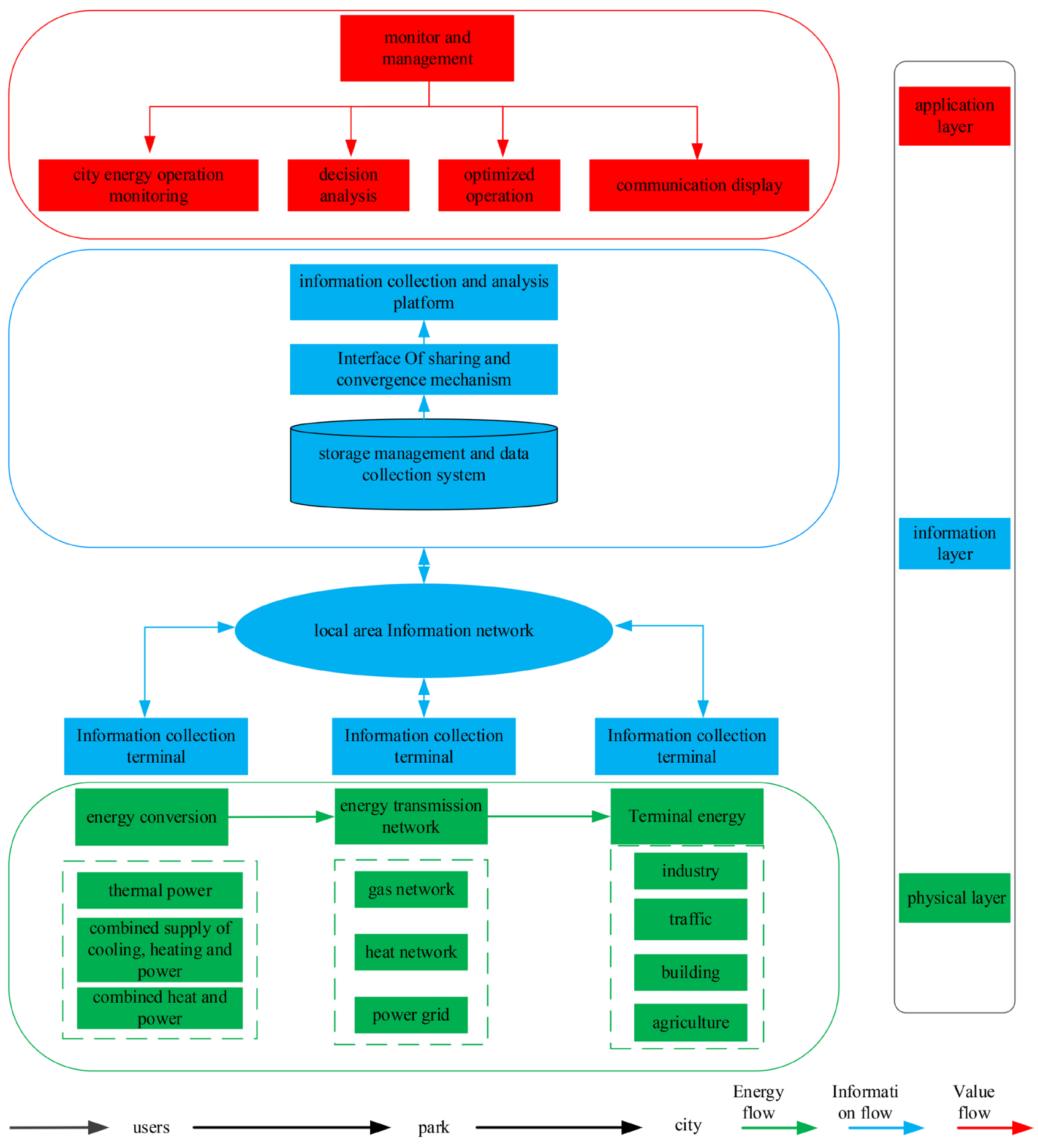

Figure 2. Physical layered construction of smart energy.

foundation and realize the intelligent upgrade of points and lines in the way of horizontal and vertical combination. Build a city-level information collection and analysis platform and complete the construction of the city energy control brain. Combine with other areas of the city to realize the construction of the city's tridimensional information platform.

The application layer is mainly to construct an operating system that realizes 
city energy operation monitoring, decision analysis, optimized operation, and communication display. Realize the integration and coordination of energy production, conversion, consumption, storage and other links, as well as integration and coordination with other applications in smart cities, and jointly promote the construction of smart cities [5] [6].

\subsection{Implementation Path}

Relying on the construction of city energy Internet, the construction of city's smart energy follows the principle of top-level and universal priority development and independent development of the respective systems under the same rules [7]. It is mainly divided into four stages:

1) Top-level planning and design stage: Form a comprehensive city smart energy top-level plan, formulate a complete and compatible construction from different levels to different scopes. Form a unified communication protocol, data interface, basic data types and metadata formats. Establish unified energy data transmission and storage specifications and management systems to form a top-level framework structure that meets the needs for independent development and integration and sharing of energy data among multiple parties. Build a unified data platform at the city level, and conduct pilots of data aggregation for different energy subjects. Study and design appropriate business models and security systems.

2) Subsystem-level development stage: All energy subsystems and application subsystems will be developing in the direction of intelligence, cleanness, efficiency, and reliability. Break down planning barriers between tightly integrated energy varieties and fields, and realize multi-energy collaborative planning such as electrical cooling and heating, etc. Preliminarily establish physical connection between different energy systems. Demonstrate city energy internet projects and business models.

3) Cross-system-level development stage: Basically break down the physical barriers between energy systems and realize the energy circulation within the city energy Internet through the conversion of various energies. Achieve information sharing within the city energy Internet and build an information physical fusion system of the city energy Internet through the measurement equipment, communication transformation protocol, information mining technology, data storage analysis technology, etc. in diverse energy systems. Promote and apply demonstration projects.

4) Platform-level development stage: The city energy internet comprehensive platform and various sub-platforms are established and continue to operate. The construction of ecological smart city is completed when market barriers are broken and energy resources are efficiently allocated. Based on various emerging technologies such as block chain and the price response mechanism of the energy market, all parties can actively participate in the optimization of energy flow and realize the unification of energy flow and information flow, and value flow. 
Finally, the intelligentization of city's smart energy is fully realized.

From the perspective of economic benefits, the construction of smart energy can improve energy efficiency from all links, save energy consumption expenses, improve the competitiveness of enterprise products, and drive the development of related industries. The first is to improve energy efficiency and reduce total energy consumption. Overall energy efficiency is estimated to be increased by about $7 \%-8 \%$. The second is to reduce operating costs and improve the competitiveness of enterprises. The energy consumption per unit of output value of major industrial enterprises is reduced by about $8 \%$, and the comprehensive energy cost can be reduced by about $10 \%$. The third is to promote technological innovation, promote the development of related equipment manufacturing and the information and communication industry. By 2030, the value of smart energy output is expected to reach about $0.5 \%$ - $1 \%$ of GDP.

From the perspective of environmental benefits, the construction of smart energy can bring three benefits. The first is to improve energy efficiency and reduce fossil energy consumption. The second is to improve the absorption capacity of renewable energy and achieve cleaner energy substitution. The third is to improve efficiency of energy conversion and reduce loss of energy conversion. The three factors work together to reduce emissions of pollutants and greenhouse gas caused by energy. By improving the efficiency of use of energy infrastructure, sharing energy channels, reducing the land use, improving land use efficiency, and alleviating pressure on ecological carrying.

From the perspective of social benefits, the construction of smart energy enables good interaction between energy suppliers and users. It can provide simple and convenient energy services, improve user's convenience and satisfaction. It can optimize the energy structure and ensure safe and reliable supply of energy. It can improve energy service efficiency, optimize business environment and enhance city image.

\section{Task Analysis}

Based on the framework and path of smart energy, adapt to local conditions and take advantage of local resource advantages to efficiently promote the construction of the energy IoT, lead the demonstration of city energy revolution.

\subsection{Focus on Improving Smart Energy Infrastructure and Realizing Value Potential of Energy Data}

By further optimizing the energy physical infrastructure, upgrading the informatization of the energy system, effectively collecting, storing, processing, and applying data, the energy data of various elements such as electricity, heat, cold, oil, gas, and transportation in the city energy system shall be integrated and optimized to effectively tap the value of energy data.

1) Construction of a unified data platform for smart energy.

a) The government leads the construction of city energy data centers, who 
collects various energy data resources such as electricity, gas, oil, coal, cold and heat.

b) Forecast of energy supply and demand, corelate of energy relationship, and analysis of energy efficiency through energy big data.

c) Establish a data sharing mechanism to ensure the safe sharing of data and improve the ability to integrate data.

d) Build a data management approach to driving business with data.

2) Information system construction of energy system.

a) Corresponding energy companies shall construct subsystems in the energy system by themselves, and collect data from production, transmission, storage, metering, use, marketing and other links to realize the visual and independent operation of the information subsystem.

b) Strengthen the construction of integrated energy service subsystems. Make comprehensive energy service management decisions based on big data analysis. Strengthen digitization of service in the process of operation, management and control. Optimize operation strategies of energy supply and dispatch. Build service systems and provide value-added services to customers.

3) Construction of smart energy standards.

a) Unified and standardized access to energy IoT infrastructure.

b) Establish energy consumption standards for industrial production.

c) Establish a database of energy efficiency standards.

\subsection{Focus on Building a Smart Energy Supply System to Ensure the City Energy Safely and Reliablely Supplied}

Adjust the structure of city energy supply to diversification goals and increase the promotion and utilization of clean energy. Make use of the basic function of the power grid as the main carrier of resource allocation and ensure its safe and reliable operation. Promote the coordinated operation and complementarity of multiple energy subsystems and accelerate demonstration of comprehensive energy engineering to realize multi-energy interconnection.

1) Construction of supply systems of multiple smart energy

a) Construction of strong smart grid. Reinforce the main network, transform old substations, promote the safe operation of power grid infrastructure, improve power quality, and ensure reliable power supply. Build a standard distribution network to optimize the power supply path, and enhance the distribution network's ability to carry various energy sources for convenient access. Disseminate state estimation technology of distribution network.

b) Upgrade and rebuild natural gas and oil supply system. Reasonably increase the layout of natural gas and oil passages, and build regional gas storage groups to ensure the safety and reliability of city gas and oil supply.

c) Development and utilization of renewable energy. Make full use of the large amount of organic waste in industry, agriculture or city life to alleviate the situation of power shortage. Use geothermal energy, water energy, wind energy, solar energy and other resources to promote clean energy substitution according to 
local conditions.

d) Carry out "multi-station integration" demonstration project. Relying on the good foundation of power grid informatization, carry out the "multi-station integration" demonstration project. Make full use of the resources of the comprehensive energy station, save the construction cost of communication base stations, and realize the interconnection of multiple energy sources.

\subsection{Focus on Upgrading Smart Energy Consumption Methods and Promoting Clean and Efficient Use of Urban Energy}

Through clean substitution, intelligent energy-saving transformation and intelligent monitoring, we will vigorously improve the energy efficiency level, accelerate the re-electrification process in all walks of life, and build a comprehensive energy-saving pattern for city transportation, construction, industry, and residential life.

1) Promotion and construction of smart buildings.

a) The project of energy monitoring terminals of public building connected to energy monitoring terminals such as smart sockets shall achieve visualization and dynamic interaction of energy statistics monitoring on the same platform, as well as energy consumption.

b) The project of cold storage and heat storage of public buildings shall reduce energy consumption costs and improve the power grid peaking capacity by using the peak-valley electricity price policy.

c) The project of real-time demand response for air-conditioning load of public buildings shall achieve centralized management of air-conditioning load on user side.

d) The project of clean heating shall use natural gas, electricity, geothermal, biomass, solar energy, industrial waste heat, clean coal (ultra-low emissions), nuclear energy and other clean energy sources to achieve low-emission and low-energy heating through efficient energy systems.

2) Intelligent construction of green transportation.

a) The construction of smart car networking shall reduce the radius of charging services and achieve autonomous collaborative operation of "net-pile-car".

b) The construction of a smart street light management system shall reduce the difficulty and cost of maintenance of street light facilities through remote management and mobile management. It shall also achieve the effect of high efficiency and energy saving [8].

c) According to local conditions, various intelligent measures for different regions, such as port and shore power, clean heating and other special projects shall be carried out [9] [10].

3) Optimization of industry energy-using.

a) Energy consumption monitoring in industrial production. Monitoring and acquisition equipment, integration of energy system equipment status monitoring, scheduling automation and other production and operation information 
shall be connected to high energy-consuming industries to achieve a high degree of automation and informationization of industrial energy systems.

b) Energy-saving transformation of agricultural production. Improve local agricultural production conditions. Improve water resource utilization efficiency and comprehensive agricultural production capacity. Eliminate high-pollution dried coal-burning and oil-burning facilities and actively guide users to use environmental-friendly energy-saving heating and drying technologies, such as electrical boilers and air-source heated pumps.

c) Optimization of energy consumption in the service industry. Promote low-carbon construction, all-electric kitchens, and electrified line transformation projects to ensure the energy can be used safely and cleanly in traditional service industries.

\subsection{Focus on Building a Smart Energy Management and Service System to Promote a High-Quality Development of City}

Explore the establishment of new business applications and value-added services based on new technologies such as big data, cloud computing, the IoT (Internet of Things), artificial intelligence, etc. Build an energy management service system covering energy subjects such as users, enterprises, governments, etc. Achieve transparent and efficient modern energy supervision and guidance control of total energy consumption to promote high-quality development of city.

1) Capacity building for smart services.

a) Convenient service for enterprises to receive electricity and gas. Streamline the approval process of electricity and gas, reduce the access cost, and improve the enterprise's sense of electricity-using and gas-using.

b) Convenient and interactive services for government affairs information. Actively share government affairs information with power grid companies and gas companies to realize the interconnection of information such as addresses, identities, and public services. Let users experience the convenience of government services through channels such as APP and Wechat.

c) Building energy efficiency evaluation services. Based on the inspection work of building energy consumption and energy usage system, it provides free energy efficiency evaluation services for public buildings and residential buildings. It also taps the energy-saving potential of buildings and motivates users to participate in energy conservation and emission reduction.

d) Intelligent operation and maintenance services. Through the operation and maintenance service system of online diagnosis and offline operation and maintenance, the core functions of transparent management, intelligent diagnosis and auxiliary decision-making of energy stations are realized.

e) Energy basic information statistics business. Strengthen the statistical work of the whole process of energy in the region. Strengthen the statistical verification of basic energy data. Grasp the actual situation of city energy supply and demand and implement the data foundation for energy-related work. 


\section{Conclusion}

The construction of smart energy includes the intelligent construction of energy infrastructure and all aspects of energy. It is strongly related to industries that use energy closely such as smart economy, smart transportation, smart buildings, and smart people's livelihood. However, it has shown mutual reference that between the construction of smart energy and wisdom governance, smart supervision, information security, etc. Therefore, the top-level design of smart energy needs to take advantage of the functional characteristics of smart city subsystems to give full play to the synergies between energy systems to maximize energy value.

\section{Conflicts of Interest}

The authors declare no conflicts of interest regarding the publication of this paper.

\section{References}

[1] National Development and Reform Commission, National Energy Administration, Ministry of Industry and Information Technology. (2016) Guiding Opinions on Promoting the Development of "Internet +" Smart Energy. City Gas, No. 4, 4-9.

[2] Li, J. Vienna's Experience in Promoting the Construction of 'Green City' with the Framework of 'Smart City'. Environmental Protection, No. 14, 63-66.

[3] Zhang, C., Han, X. and Li, J. (2018) A Comparative Study of Smart City Construction between China and Singapore under the Background of Big Data. Modern Information, 38, 128-133+143.

[4] Deng, H. (2017) Establishing 'Integrated Smart Energy Service System with Power Grid as a Link' in Beijing's New Airport Area. China Power Enterprise Management, No. 31, 50-51.

[5] Dang, A., Zhen, M., Wang, D., et al. The Development Process and Trend of New Smart City in China. Science \& Technology Review, 36.

[6] Desouza, K.C., Smith, K.L. and Wang, K. (2018) Catching Up with the Trend of Smart Cities: Are We Lost. Exploration and Controversy, 346, 6-12 + 17+143.

[7] Wang, X. and Chen, X. (2018) Research on Top-Level Design of Urban Smart Energy System under Urban Energy Reform. China Electric Power, No. 8, 85-91.

[8] Tang, J., Yang, X., Duan, X., et al. (2018) Construction and Research on Energy Saving System of Smart City Grid with Street Lamp Charging Piles. Energy Conservation and Environmental Protection, 293, 56-57.

[9] Li, B, Feng, T., Niu, H., et al. (2018) Research on Key Technologies of Smart Energy System Planning and Regulation for Civil Aviation Airport. Energy Conservation, 37, 6-9.

[10] Dong, H., Zeng, Z. and Zhou, H. (2018) Application of Smart Energy in Energy Storage. Environmental Technology, 36, 102-105+119. 